\title{
Contrarian Technical Trading Rules: Evidence From Nairobi Stock Index
}

Massoud Metghalchi, University of Houston-Victoria, USA

John Kagochi, University of Houston-Victoria, USA

Linda A. Hayes, University of Houston-Victoria, USA

\begin{abstract}
We apply several popular technical trading rules in the normal way and a contrarian way to daily data of the Nairobi Stock Index from 9/12/2006 to 4/18/2013. The contrarian usage of popular technical trading rules implies that when a technical trading indicator emits buy (sell) signals, we do the opposite and sell (buy) the index. Results from the study support the predictive power of contrarian technical trading rules. We also investigate whether a trader can use the predictive power of contrarian technical rules to beat the profitability of the buy-and-hold strategy considering both transaction costs and risk. Designing four strategies of various contrarian trading rules, we conclude that it is possible to beat the buy-and-hold strategy even considering transaction costs and risk.
\end{abstract}

Keywords: Technical Analysis; Trading Indicators; Market Efficiency

\section{INTRODUCTION}

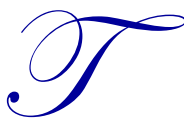

echnical Analysis (TA) includes a broad range of trading rules based on past prices and volume to predict stock prices. Trend is one of the most important concepts in technical analysis. Pring (1991, p. 3) points out that "the art of technical analysis, for it is an art, is to identify a trend reversal at a relatively early stage and ride on that trend until the weight of evidence shows or proves that the trend has reversed." A technician can use various indicators that are based on past prices and volumes to determine changes in trend and predict future prices. Since the mid-1980s, a myriad of research on technical analysis has been done for many countries, but we have not found an analysis for Kenya.

The purpose of this paper is twofold. First, we investigate whether several popular indicators have predictive powers in the case of the Nairobi Stock Index (NSI). And, second, if technical analysis has predictive power, we investigate whether it is possible for a trader to design a trading strategy to beat the buy-and-hold (B\&H) strategy after considering both risk and transaction costs.

The Nairobi Securities Exchange (NSE) was founded in 1954 and was restricted to Europeans until the early 1960s. In 1963, Kenya became independent, and the NSE experienced steady growth for several years igniting confidence in the market. The exchange handled a number of highly oversubscribed issues. The inflationary pressures of the 1970s oil crisis introduced inflationary pressures in the economy that led to depressed share values, although the market was able to recover. Capital gains tax was introduced in 1975 and suspended in 1985 (NSE, 2013). In the years that followed, the NSE saw an increase in the number of stockbrokers, the introduction of investment banks, and the establishment of custodial institutions and credit rating agencies. By 2013, the number of listed companies had increased to 55.

The NSE currently has an average daily trading volume of over USD 5 million and a total market capitalization of approximately USD 20 billion as of June 2013. Apart from equities, the NSE also trades in government and corporate bonds with an average daily bond trading of approximately USD 60 million making it one of the largest in sub-Saharan Africa (NSE, 2013). 
In this paper we use several popular trading rules to analyze the NSI; Exponential Moving Averages (EMA), Relative Strength Indicator (RSI), Stochastic, Parabolic Stop and Reverse (PSAR), Moving Average Convergence Divergence (MACD), and Directional Moving System (DMS). We apply each of these trading rules in the normal way and in a contrarian way to the NSI. As an example, we use the moving average 50 rule to illustrate the difference between the normal way and the contrarian way of using a trading rule. For the normal trading rule, a trader will go long when price penetrates the moving average 50 from below (a trend is initiated) and will go short or liquidate the position when the price breaks the moving average 50 from above. However, the contrarian technical trading rule is the opposite. When the price penetrates the moving average 50 from below, then the trader will go short or liquidate the position, and when the price penetrates the moving average 50 from above, the trader will go long.

This article is organized in five sections. Section I and Section II are the Introduction and Literature Review, respectively. Section III discusses data and methodology, Section IV presents empirical results on various technical trading rules, and Section $\mathrm{V}$ provides remarks and conclusions drawn from this study.

\section{LITERATURE REVIEW}

The study of market efficiency has played a major role in academia over the past half century. For Fama (1970), security prices fully reflect the available information, and price changes will be unpredictable or follow a random walk. Studies before the 1980s overwhelmingly supported the "random walk" hypothesis. Examples of these studies include Larson (1960), Osborne (1962), Alexander (1964), Granger and Morgenstern (1963), Mandelbrot (1963), Fama (1965), Fama and Blume (1966), Van Horn and Parker (1967), and Jensen and Benington (1970). This research resulted in many ardent believers of the efficient-market hypothesis (EMH).

By the mid-1980s a few inspiring articles in technical trading created some doubt about the uselessness of technical trading (Sweeney, 1986; Lukac et al., 1988; Brock et al., 1992). Sweeney (1986) concludes that trading rules work in foreign exchange markets. Lukac et al. (1988) find four technical trading rules that statistically beat the buy-and-hold strategy. A seminal paper by Brock, Lakonishok, and LeBaron (1992, BLL thereafter) concludes that their "results are consistent with technical rules having predictive power."

Following BLL's techniques, many researchers have investigated whether technical analysis could have predictive powers. Bessembinder and Chan (1995) conclude that BBL's rules have predictive powers for Japan, Hong Kong, South Korea, Malaysia, Thailand, and Taiwan. Bessembinder and Chan (1998) confirm the basic BLL results but argue that the predictive power of trading rules need not be inconsistent with market efficiency when considering transaction costs. Gencay (1998a, 1998b) and Ratner and Leal (1999) also support the predictive power of technical trading rules. Kwon and Kish (2002) apply moving average rules to the New York Stock Exchange (NYSE) index and conclude that the technical trading rules have the potential to capture profit opportunities when compared to the buy-and-hold strategy. Metghalchi and Chang (2003) apply a variety of moving average rules to the Italian Stock Index and support the predictive power of technical trading rules.

In a survey of literature, Park and Irwin (2007) review a total of 137 papers on technical trading from 1960 until August 2004. They divide the empirical literature into two groups according to the features of the testing procedures. Early studies (first group) go from 1960 to 1988, while modern studies (second group) begin with Lukac et al. (1988) and include studies up to 2004. Results from the Park and Irwin (2007) review conclude that early studies did not support the hypothesis of profitability of technical trading for equity markets. However, of the 95 more recent studies reviewed, the researchers found 56 supported profitability of technical trading rules, 20 showed negative evidence, and the remaining 19 studies were mixed.

Other studies have been conducted after 2004 including Hsu and Kuan (2005) which show that technical trading rules are profitable for newer indices such as the NASDAQ Composite or the Russell 2000. Chang et al. (2006) apply a variety of moving average trading rules for the Taiwan stock market with the results supporting the profitability of technical trading for the Taiwan stock market. Lento (2007) examines the profitability of nine technical trading rules in eight Asian-Pacific stock markets and shows support of the profitability of technical trading. Metghalchi et al. (2008) apply moving average trading rules for the Swedish stock market and conclude that 
moving average strategies could be profitable even after accounting for transaction costs and data snooping. Zhou and Zhou (2009) believe that moving average rules add value to asset allocation strategies. Chong et al. (2010) apply a few popular technical trading indicators to BRIC countries and conclude that, after accounting for transaction costs, technical trading only works for the Russian market. Metghalchi and Garza-Gomez (2011) apply a half dozen popular trading rules to the Abu Dhabi stock market and conclude that, although technical trading rules have predictive powers, the extra profits do not compensate for transaction costs and risk. Elsewhere, Metghalchi et al. (2012) apply moving average trading rules for 16 European countries and conclude that technical trading rules work better for smaller countries.

Since 1995, there are several studies that do not support profitability of technical trading. Raj and Thurston (1996) apply moving average rules for the Hang Seng Futures Index and conclude that moving average rules could not beat the buy-and-hold strategy. Hudson et al. (1996) apply the BLL rules to the United Kingdom stock market returns and conclude that technical trading rules do not generate excess returns after considerations for transaction costs. Szakmary et al. (1999) find that, while trading rules on individual stocks perform poorly, trading rules tend to earn statistically significant abnormal returns when considering the overall Nasdaq index. However, the researchers believe that, since there is a high level of transaction costs associated with Nasdaq trading, the abnormal returns are not economically significant. Coutts and Cheung (2000) analyze the Hang Seng returns and conclude that both the moving average and trading breakout rules fail to provide positive abnormal returns, net of transaction costs. Taylor (2000) investigate several moving average rules for the U.S. and U.K. stock indices and find that, on average, the break-even one-way transaction cost is low $(0.35 \%)$ for profitable technical trading. Ready (2002) points out the apparent success of the BLL moving average rules is a spurious result of data snooping and need not persist in the future. Lesmond et al. (2004) conclude that the abnormal momentum returns create an illusion of trading profit opportunities when, in fact, none exists. Dunis and Chen (2005) point out that the use of technical trading rules such as MACD perform poorly in volatile markets. Chen et al. (2011) conclude that economical profits cannot be rendered from technical analysis in the Taiwan stock market after consideration of transaction costs.

\section{DATA AND METHODOLOGY}

Data for nominal interest rates was obtained online from the World Bank, world development indicators website (World Bank, 2012). We use the daily data for the Nairobi Stock Index (NSI) from 9/12/2006 to 4/18/2013. We obtained the daily close, high, low, and open from the NSE database. The NSI is a capitalization-weighted index of all the companies listed on the Nairobi Stock Exchange. The NSE trades on all business days except when there is a National Holiday, and live trading on the automated trading systems of the Nairobi Stock Exchange was implemented in 2006. The list of stocks in the NSI has been growing and, as of June 2013, there are 55 stocks listed in the index.

All data are in the local currency, the Kenya Shilling (KES). We compute daily returns as changes in logarithms of the index price. Although changes in the stock price index do not include daily dividend yields, we do not expect this omission to alter the results of our analysis. Mills and Coutts (1995) review the literature regarding dividends and conclude that any bias in the results due to dividend exclusion will be minimal. The same conclusion is supported by Draper and Paudyal (1997).

The popular indicators applied to the NSI are the exponential moving average rules (EMA), Moving Average Convergence Divergence (MACD), Directional Movement System (DMS) Relative Strength Indicator (RSI), Parabolic Stop and Reverse (PSAR), and Stochastic (See the appendix for more details). We first describe the normal way of using each trading rule and then describe the contrarian use of each rule. A trader using the trading rules for EMA the normal way would buy (sell) the index when the short-term moving average exceeds (is less than) the long-term exponential moving average by a specified percentage (band). In this study we use long term EMA of 30, 50, and 100 (no band is used since the results are very similar with bands). As for the short moving average, like the BLL study, we use one (1) day (the raw index price) moving average. Thus, for normal EMA trading rules, a buy signal is emitted when the index level breaks the long EMA from below, and a sell signal is emitted when the index level breaks the long EMA from above. The contrarian trading rule is the opposite, a buy signal is emitted when the index level breaks the long EMA from above (price goes below EMA) and a sell signal is emitted when the index level breaks the long EMA from below ( $\mathrm{P}>\mathrm{EMA}$ ). This contrarian rule is not typically used and, to our knowledge, 
has not been applied and reported in any other study. We assume that a trader following this strategy (and other strategies like PSAR, RSI, MACD, DMS) could presumably estimate the index price that would trigger the buy and sell signals at the close and initiate a limit order at the close of the market to implement the trading rule.

In the case of the contrarian EMA rule, if the closing price is less than the long EMA, then the trader will be in the market the next day by buying the index at the closing price (next day will be a buy day). The next day's return will be the difference between the logarithm of the closing price the next day and the logarithm of closing price the previous day. On the other hand, if the closing price is greater than the long EMA, then the trader will sell the index (closes all positions) at the closing price and will be out of the market the next day (next day will be a sell days, or the trader will be out of the market). In this way, the trader is either in the market (buy days) or out of the market (sell days).

The second indicator used in this paper was created by Wells Wilder and presented in his 1978 book, New Concepts in Technical Trading Systems. The Relative Strength Indicator (RSI) measures the strength of a security against its history of price change by comparing up days to down days over a period of time. Wells Wilder suggested using 14 days period. The RSI can range from zero to 100. In an uptrend market the RSI stays above 50 and, in a down trend market, the RSI stays below 50. Therefore, the normal trading rule would be that the trader is in the market when the RSI is above 50 and out of the market as soon as the RSI goes below 50. However, the contrarian RSI rule is the opposite; thus in this study, a sell signal is emitted when the RSI is above 50 and the trader is out of the market when the RSI indicator is above 50. The trader will get in the market as soon as the RSI goes below 50 .

Gerald Appel (1974) created the third indicator used, the Moving Average Convergence Divergence indicator or MACD. This indicator is calculated by subtracting 26-period EMA from 12-period EMA of closing prices. The resulting difference oscillates around the zero line. For the normal trading rule, if MACD is above (below) zero, then a buy (sell) signal is emitted. Whereas, the contrarian trading rule is the opposite and, in this study, a sell signal is emitted when the MACD is positive, and we will be out of the market as long as the MACD stays above zero. We will be in the market as soon as the MACD becomes negative and will be in the market as long as MACD is below zero.

Another trend following indicator used in the study is Welles Wilder's (1978) Parabolic SAR (Stop And Reversal). PSAR is normally used to set trailing price stops, and is, therefore, a stop-loss system. The stop is continuously adjusted in the direction of the position. In an uptrend market the indicator is below the price and, in a down trend, PSAR is above the price. The normal trading rule with PSAR implies that a trader is in the market when the price is above the PSAR value and out of the market when the index is below the PSAR value. Again, the contrarian PSAR rule is the opposite, and we will be in the market (buy days) when the price (the index level) is below the PSAR value and out of the market when the price is above the PSAR value.

Although it is not clear who developed this model, the Stochastic indicator promoted by George Lane (1985) is also used in this study. The Stochastic indicator shows the location of a security's current closing price relative to its price range over a given time period. The fast stochastic is called $\% \mathrm{~K}$. Next, a second line is estimated as the moving average 3 of $\% \mathrm{~K}$ and is called $\% \mathrm{D}$. A normal trading rule based on this indicator is to be in the market when $\% \mathrm{~K}$ is above $\% \mathrm{D}$, and the $\% \mathrm{D}$ line is increasing (buy days); otherwise, the trader will be out of the market (sell day). Therefore, the contrarian stochastic trading rule is the opposite and, in this paper, we will be in the market if $\% \mathrm{~K}$ is below $\% \mathrm{D}$, and the $\% \mathrm{D}$ line is decreasing (buy days); otherwise, we will be out of the market (sell day).

The last indicator used in this paper is Wells Wilder's (1978) Directional Movement System (DMS) indicator. DMS consists of two directional movements, a positive directional movement (+DM) and a negative directional movement (-DM). The usual trading for this indicator is to be in the market as long as +DM is above $\mathrm{DM}$ and be out of the market when $+\mathrm{DM}$ is less than $-\mathrm{DM}$. In this paper we also use the contrarian DMS; thus, we will be in the market if $+\mathrm{DM}$ is below $-\mathrm{DM}$ and will be out of the market if $+\mathrm{DM}$ is above -DM. 
For each trading rule, we define the mean buy $\left(X_{\mathrm{B}}\right)$, the mean sell $\left(X_{\mathrm{S}}\right)$ and the mean buy-and-hold $\left(X_{\mathrm{H}}\right)$ as follows:

$$
X_{\mathrm{B}}=\frac{1}{N_{\mathrm{B}}} \sum R_{\mathrm{B}}
$$

$X_{\mathrm{S}}=\frac{1}{N_{\mathrm{S}}} \sum R_{\mathrm{S}}$

$X_{\mathrm{H}}=\frac{1}{N} \sum R$

Where $N_{\mathrm{B}}$ and $N_{\mathrm{S}}$ are the total number of buy and sell days; $N$ being the total number of observations (days); $R_{\mathrm{B}}$ and $R_{\mathrm{S}}$ are daily returns on buy and sell days; and $R$ is daily stock index returns. We perform three tests to analyze whether the mean buy returns and the mean sell returns of a particular rule is greater than the mean return of the buy-and-hold strategy and whether the mean return on buy days is greater than the mean return on sell days:

$$
\begin{array}{cccc} 
& \text { Test } 1 & \text { Test } 2 & \text { Test 3 } \\
\mathrm{H}_{0}: & X_{\mathrm{B}}-X_{\mathrm{H}} \leq 0 & X_{\mathrm{S}}-X_{\mathrm{H}} \leq 0 & X_{\mathrm{B}}-X_{\mathrm{S}} \leq 0 \\
\mathrm{H}_{\mathrm{A}}: & X_{\mathrm{B}}-X_{\mathrm{H}}>0 & X_{\mathrm{S}}-X_{\mathrm{H}}>0 & X_{\mathrm{B}}-X_{\mathrm{S}}>0
\end{array}
$$

Following Kwon and Kish (2002), the test statistic for the mean return on buy days over the mean buy-andhold return (Test 1) is:

$t=\frac{X_{\mathrm{B}}-X_{\mathrm{H}}}{\sqrt{\mathrm{VAR}_{\mathrm{B}} / N_{\mathrm{B}}+\mathrm{VAR}_{\mathrm{H}} / N}}$

Where $\mathrm{VAR}_{\mathrm{B}}$ and $\mathrm{VAR}_{\mathrm{H}}$ are the variances of buy and buy-and-hold returns, respectively. The above formula (4) is also used to test the mean sell return over the mean buy-and-hold return (Test 2) and the mean buy return over the mean sell return (Test 3) by replacing the appropriate variables in the $t$-statistic formula.

\section{Empirical Results}

Table 1 presents the summary statistics for the NSI; the average daily return is almost zero $(0.00003 \%$ per day) with a standard deviation of 10.253 percent; this standard deviation is much higher ( 8 to 10 times higher) when compared with other countries cited in the literature review, implying that the NSI is extremely volatile. The number of observations (days) is 1584 and, therefore, we cannot reject the hypothesis that the mean return is different from zero. The skewness is greater than zero implying return distributions are not symmetric. Also, the Kurtosis is extremely high, implying that the return distributions are not normal. In fact the Jarque-Bera test rejects normality of

\begin{tabular}{|c|c|c|c|c|c|c|c|c|}
\hline & $\begin{array}{c}\text { Mean } \\
\text { Return \% }\end{array}$ & $\begin{array}{c}\text { Standard } \\
\text { Deviation \% }\end{array}$ & Skewness & Kurtosis & $\rho 1$ & $\rho 2$ & $\rho 3$ & $\mathbf{N}$ \\
\hline VSI & 0.00003 & 10.254 & -3.20 & 515.48 & -0.36 & -0.10 & -0.04 & 1584 \\
\hline
\end{tabular}
returns. The first and second order autocorrelations are negative and significant but the third order is small and insignificant.

Table 1: Summary Statistics for NSI (9/12/2006 to 4/18/2013)

Note: NSI denotes Nairobi Stock Index

After applying the above trading rules, we found that results were negative when using the trading rules in the normal way. Therefore, Table 2 reports the results of the contrarian usage of the trading rules. For each 
contrarian rule, we report the mean returns on buy days, sell days, and buy minus sell days. We also report the standard deviations of returns on buy and sell days, total number of buy and sell days, and total number of signals in and out of the market if a trader follows that particular rule. The numbers in the parentheses are the $t$-statistics (Equation 4) that test the difference of the mean buys and mean sells from the mean of buy-and-hold, and the mean buys-sells from zero. In the paper, we compare all $t$-stats with 1.645 which is the critical $t$-value at 5 percent level for large numbers of observations for a one-tail test.

The first row of Table 2 shows the results of the contrarian trading rule of EMA20; we will be in the market (buy days) if the MA1 (Index level) is less than EMA20 and out of the market (sell days) if the index level is greater than or equal to EMA20 (we also used a $1 \%$ band and the results were almost the same). The mean buy and sell returns for EMA20 rule are $0.00879(0.879 \%$ per day $)$ and $-.00648(-0.648 \%$ per day $)$ with the daily standard deviation of 15.029 and 3.859 percent per day, respectively. It is interesting to note that unlike BBL and many other studies cited in the literature review, the standard deviation of buy days is much higher than the standard deviation of sell days, implying that the NSI is much more volatile in uptrend markets than downtrend markets. The mean buy and sell returns have the correct signs and are much higher than the unconditional mean return for the entire period ( $0.03 \%$ per day). However, because of the very high standard deviation of buy days, the $t$-statistics for the mean buy days are not significant, implying that we cannot reject the hypothesis that the mean buy return is greater than the unconditional mean. Given that the standard deviation of the sell days is much smaller than buy days and the mean sell days (absolute value) is much higher than the unconditional mean, the $t$-statistics for sell days are statistically significant; we, therefore, reject the null hypothesis that the mean sell return is less than the unconditional mean and conclude that the absolute value of the mean sell returns is greater than the unconditional mean returns. Looking at buy minus sell days, all the signs are positive with highly significant t-statistics, rejecting the null hypothesis that the mean buy returns are less than the mean sell returns. Columns 7 and 8 report the number of buy and sell days. Using the EMA20 rule as an example, on the average $42.55 \%$ of the time we are in the market (buy days) and $57.45 \%$ out of the market (sell days). The last column reports the total number of buy and sell signals over the entire period.

Table 2: Statistical Results of Various Contrarian Trading Rules

Results for daily data from 9/12/2006 to 4/18/2013. The first column identifies technical trading rules. Buy and Sell are the daily average percentage returns of the buy and sell days. $\mathrm{N}_{\mathrm{b}}$ and $\mathrm{N}_{\mathrm{s}}$ are the number of buy and sell days. $\mathrm{SD}_{\mathrm{b}}$ and $\mathrm{SD}_{\mathrm{s}}$ are standard deviations of buy and sell days. The numbers in the parentheses are the t-statistics testing the difference of the mean buy and mean sell from the unconditional mean, and mean buy-sell from zero. Numbers marked with asterisks are significant at the $5 \%$ level for a one-tailed test, $\left(t_{\text {crit. }, 0.05}=1.645\right)$.

\begin{tabular}{|c|c|c|c|c|c|c|c|c|}
\hline Rules & Buy & Sell & Buy - Sell & $\mathbf{S D}_{b}$ & $\mathbf{S D}_{\mathrm{s}}$ & $\mathbf{N}_{b}$ & $\mathbf{N}_{\mathrm{s}}$ & Total Signal \\
\hline EMA20 & $\begin{array}{c}0.00879 \\
(1.38)\end{array}$ & $\begin{array}{l}-0.00648 \\
(-2.26)^{*}\end{array}$ & $\begin{array}{c}0.01527 \\
(2.57)^{*}\end{array}$ & 0.15029 & 0.03859 & 674 & 910 & 257 \\
\hline EMA50 & $\begin{array}{c}0.00746 \\
(1.10)\end{array}$ & $\begin{array}{l}-0.00490 \\
(-1.77)^{*}\end{array}$ & $\begin{array}{c}0.01236 \\
(1.95)^{*}\end{array}$ & 0.15719 & 0.03272 & 631 & 953 & 181 \\
\hline EMA100 & $\begin{array}{c}0.00470 \\
(0.70)\end{array}$ & $\begin{array}{c}-0.00336 \\
(-1.24)\end{array}$ & $\begin{array}{c}0.00806 \\
(1.31)\end{array}$ & 0.15582 & 0.02559 & 658 & 899 & 81 \\
\hline RSI & $\begin{array}{c}0.00789 \\
(1.22)\end{array}$ & $\begin{array}{c}-0.00562 \\
(-1.99)^{*}\end{array}$ & $\begin{array}{c}0.01350 \\
(2.23)^{*}\end{array}$ & 0.15263 & 0.03573 & 662 & 922 & 221 \\
\hline PSAR & $\begin{array}{c}0.00280 \\
(0.47)\end{array}$ & $\begin{array}{c}-0.00239 \\
(-0.83)\end{array}$ & $\begin{array}{c}0.00519 \\
(0.95)\end{array}$ & 0.14412 & 0.03989 & 737 & 847 & 127 \\
\hline MACD & $\begin{array}{c}0.00213 \\
(0.32)\end{array}$ & $\begin{array}{c}-0.00140 \\
(-0.51)\end{array}$ & $\begin{array}{c}0.00353 \\
(0.57)\end{array}$ & 0.15601 & 0.03432 & 640 & 944 & 56 \\
\hline DMS & $\begin{array}{c}0.00805 \\
(1.22)\end{array}$ & $\begin{array}{l}-0.00545 \\
(-1.91)^{*}\end{array}$ & $\begin{array}{c}0.01350 \\
(2.18)^{*}\end{array}$ & 0.15398 & 0.03832 & 642 & 942 & 203 \\
\hline Stochastic & $\begin{array}{c}0.00656 \\
(1.10) \\
\end{array}$ & $\begin{array}{c}-0.00549 \\
1.85)^{*}\end{array}$ & $\begin{array}{l}0.01206 \\
(2.18) *\end{array}$ & 0.14351 & 0.04418 & 752 & 859 & 820 \\
\hline
\end{tabular}

Note: Contrarian rules are as follow: For EMAs, if P < EMA in the market, otherwise out of the market. If RSI < 50, in the market, otherwise out of the market. If PSAR > price, then in the market, otherwise out of the market. If MACD < 0, then in the market, otherwise out of the market. For DMS, If $+\mathrm{DM}<-$ DI then in the market, otherwise out of the market. For Stochastic, if $\% \mathrm{~K}<\% \mathrm{D}$, and $\% \mathrm{D}$ decreasing, then in the market, otherwise out of the market.

The results of Table 2 support the predictive power of contrarian technical trading rules. For five out of eight contrarian rules, the mean buy minus sell returns are positive with highly significant $t$-statistics, rejecting the 
null hypothesis that the mean buy returns equal the mean sell returns. Also for five out of eight contrarian rules, the mean sell returns are negative with highly significant $t$-statistics, rejecting the null hypothesis that the mean sell returns is less than the mean of buy-and-hold returns.

The best contrarian rules are EMA20, RSI, and EMA50 with very high mean buy and sell returns compared with the unconditional mean. The DMS rule also has very high mean buy and sell returns when compared with the unconditional mean. Although the contrarian Stochastic trading rule has very high mean buy and sell returns, it is not one of the best trading rules since it implies the trader is in and out of the market many more times resulting in very high transaction costs that will be discussed in Section IV. If the stock market is efficient, then we should not be able to apply trading rule models with significant differences in their mean buy and sell returns, such as the results in Table 2 and also Table 3.

Table 3: Statistical Results for Combined Contrarian Trading Rules

Results for daily data from 9/12/2006 to 4/18/2013. The first column identifies technical trading rules. Buy and Sell are the daily average percentage returns of the buy and sell days. $\mathrm{N}_{\mathrm{b}}$ and $\mathrm{N}_{\mathrm{s}}$ are the number of buy and sell days. $\mathrm{SD}_{\mathrm{b}}$ and $\mathrm{SD}_{\mathrm{s}}$ are standard deviations of buy and sell days. The numbers in the parentheses are the t-statistics testing the difference of the mean buy and mean sell from the unconditional mean, and mean buy-sell from zero. Numbers marked with asterisks are significant at the $5 \%$ level for a one-tailed test, $\left(t_{\text {crit. }, 0.05}=1.645\right)$.

\begin{tabular}{lcccccccc}
\hline \multicolumn{1}{c}{ Rules } & Buy & Sell & Buy-Sell & SD $_{\mathbf{b}}$ & SD $_{\mathbf{s}}$ & $\mathbf{N}_{\mathbf{b}}$ & $\mathbf{N}_{\mathbf{s}}$ & Total Signals \\
\hline EMA20 \& & 0.01007 & -0.00573 & 0.01580 & 0.16199 & 0.03207 & 577 & 1007 & 219 \\
DMS & $(1.39)$ & $(-2.03)^{*}$ & $(2.31)^{*}$ & & & & \\
EMA20 \& & 0.00947 & -0.00618 & 0.01566 & 0.15563 & 0.03778 & 628 & 956 & 241 \\
RSI & $(1.41)$ & $(-2.18)^{*}$ & $(2.47)^{*}$ & & & & \\
EMA20 \& & 0.01140 & -0.00596 & 0.01735 & 0.16655 & 0.03697 & 546 & 1038 & 219 \\
EMA50 & $(1.50)$ & $(-2.12)^{*}$ & $(2.40)^{*}$ & & & & 1049 & 183 \\
EMA50 \& & 0.00992 & -0.00502 & 0.01494 & 0.16843 & 0.03676 & 535 & & \\
DMS & $(1.28)$ & $(-1.79)^{*}$ & $(2.03)^{*}$ & & & & & \\
EMA50 \& & 0.00972 & -0.00550 & 0.01522 & 0.16332 & 0.03519 & 575 & & \\
RSI & $(1.33)$ & $(-1.97)^{*}$ & $(2.21)^{*}$ & & & & & \\
DMS \& & 0.00892 & -0.00520 & 0.01412 & 0.16104 & 0.03745 & 586 & 998 & 195 \\
RSI & $(1.25)$ & $(-1.84)^{*}$ & $(2.09)^{*}$ & & & & & \\
\hline
\end{tabular}

In Table 3 we investigate whether we can improve the results of Table 2 by combining the best trading rules. Table 3 shows the results of combining our best contrarian trading rules. For example the first row of Table 3 combines the contrarian rules of EMA 20 and DMS; we will be in the market (buy days) if the index level is less than EMA20 and if plus DM is below negative DM, otherwise we will be out of the market (sell days). We could report many more combinations but felt that, by reporting the results of six combinations, we capture the most important points of combined trading rule signals. The results of Table 3 are better than Table 2, and all buy minus sell days are positive with significant t-statistics, rejecting the hypothesis that the mean buy days is less than the mean sell days. In addition all sell days have the correct negative signs and are all significant, rejecting the hypothesis that the mean sell days are less than the unconditional mean.

We conclude that, by combining contrarian trading rules, we can improve the predictive power of technical trading. However, in any trading system, a trader has to decide what action should be taken if a rule emits a sell signal. When a trader is out of the market (sell days), the return would be zero if nothing else is done, resulting in a lower annual return; whereas a trader following the passive strategy will be in the market every day. Since total annual return depends on both buy day and sell day returns, the question becomes what strategy a trader should adopt when the rule emits a sell signal? In the next section we design a few strategies to answer this question.

\section{TRADING STRATEGIES}

Table 2 and 3 show that contrarian technical trading rules have predictive powers for the NSI; the question becomes whether a trader can apply these contrarian rules to beat the profitability of a buy-and-hold strategy considering transaction costs and risk? The profitability of contrarian trading depends on the trading strategy, especially, what position the trader should take when the rule emits a sell signal. If the trader does nothing on sell 
days, the trader's returns for sell days will be zero and the trader's annual return is equal to $\left(\mathrm{N}_{\mathrm{b}} / \mathrm{N}\right) * \mathrm{X}(\mathrm{b})+\left(\mathrm{N}_{\mathrm{s}} / \mathrm{N}\right)$ $* 0$, where $\mathrm{N}_{\mathrm{b}}, \mathrm{N}_{\mathrm{s}}, \mathrm{N}$, and $\mathrm{X}(\mathrm{b})$ are the number of buy, sell, and total number of days, and the mean buy return in a year, respectively. Four strategies are considered: (1) when the contrarian trading rules emit buy signals, the trader will be in the market and, when it emits sell signals, the trader invests the funds in the money market (long/money), (2) when the contrarian trading rules emit buy signals, the trader will be in the market and, when it emits sell signals, the trader will short the market (long/short), (3) when the contrarian trading rules emit buy signals, the trader will borrow at the money market rate and double stock investment and be in the money market when it emits sell signals (leverage/money), and (4) when the contrarian trading rules emit buy signals, the trader will borrow at the money market rate and double stock investment; when the contrarian rules emit sell signals, the trader will short the market (leverage/short). The total return on buy days for the leverage strategy is $\mathrm{TR}_{t}=2 * \mathrm{R}_{t}-\mathrm{M}_{t}$, where $\mathrm{R}_{\mathrm{t}}$ is the index return on day $t$ and $\mathrm{M}_{\mathrm{t}}$ is the daily money market rate. It should be noted that, when shorting the market, there are transaction costs involved, whereas investing in the money market does not incur any transaction costs.

For each of these four strategies, we estimate the daily return and then subtract from it the daily return of the buy-and-hold strategy to calculate the daily difference return. To test whether the average daily difference is greater than zero, we express the null and alternative hypotheses as follow:

$\begin{array}{ll}\mathbf{H}_{0}: & \text { ddif } \leq 0 \\ \mathbf{H}_{\mathrm{A}}: & \text { ddif }>0\end{array}$

The $t$-statistic for the above test is:

$t=\frac{X(\text { ddif })}{\sqrt{\operatorname{Var}(\text { ddif }) / N}}$

Where $\mathrm{X}$ (ddif) is the mean daily difference of returns of each strategy over the buy-and-hold strategy, Var(ddif) is the variance of daily difference returns, and $\mathrm{N}$ is the total number of days. Table 4 presents the results of all four strategies for four contrarian single indicator rules and six contrarian combined indicators.

Table 4: Trading Strategies

$X($ ddif $)$ is the average of daily difference between the return of each strategy and the buy-and-hold strategy. The numbers in $\mathrm{t}-$ statistic columns test whether the average daily difference is greater than zero. Asterisks imply significant at the 5 percent level or less $\left(t_{\text {crit. }, 0.05}=1.645\right)$.

\begin{tabular}{|c|c|c|c|c|c|c|c|c|}
\hline & \multicolumn{2}{|c|}{ Long/Money } & \multicolumn{2}{|c|}{ Long/Short } & \multicolumn{2}{|c|}{ Leverage/Money } & \multicolumn{2}{|c|}{ Leverage/Short } \\
\hline & $\mathbf{X}($ diff $)$ & t-stat & $\mathbf{X}($ diff $)$ & t-stat & X(diff) & t-stat & X(diff) & t-stat \\
\hline EMA-20 & 0.00396 & $5.36 *$ & 0.00743 & $5.03 *$ & 0.00754 & $2.93 *$ & 0.01100 & $3.84^{*}$ \\
\hline EMA-50 & 0.00321 & $5.01 *$ & 0.00589 & $4.60 *$ & 0.00602 & $2.34 *$ & 0.00871 & $3.11 *$ \\
\hline RSI & 0.00352 & $5.12 *$ & 0.00654 & $4.75^{*}$ & 0.00665 & $2.59 *$ & 0.00967 & $3.41 *$ \\
\hline DMS & 0.00349 & $4.69 *$ & 0.00648 & $4.36 *$ & 0.00659 & $2.56^{*}$ & 0.00959 & $3.33^{*}$ \\
\hline EMA20 \& DMS & 0.00392 & $5.15^{*}$ & 0.00729 & $4.79 *$ & 0.00744 & $2.90 *$ & 0.01081 & 3.75 \\
\hline EMA20-RSI & 0.00399 & $5.38 *$ & 0.00746 & $5.03 *$ & 0.00759 & $2.95 *$ & 0.01106 & $3.85^{*}$ \\
\hline EMA50 \& DMS & 0.00361 & $4.79 *$ & 0.00665 & $4.41 *$ & 0.00683 & 2.66 & 0.00987 & $3.43^{*}$ \\
\hline EMA50 \& RSI & 0.00378 & $5.33^{*}$ & 0.00701 & $4.94 *$ & 0.00716 & $2.79 *$ & 0.01039 & $3.65^{*}$ \\
\hline EMA20 \& EMA50 & 0.00419 & $5.54 *$ & 0.00781 & $5.17 *$ & 0.00798 & $3.11 *$ & 0.01160 & $4.03^{*}$ \\
\hline DMS \& RSI & 0.00355 & $4.73 *$ & 0.00655 & $4.37 *$ & 0.00670 & $2.61 *$ & 0.00971 & $3.37 *$ \\
\hline
\end{tabular}

The results of Table 4 are very good and show that it is possible to implement various strategies based on contrarian trading rules to beat the buy-and-hold strategy. All ten contrarian trading rules have significant $t$-statistics. $\mathrm{We}$, therefore, reject the hypothesis that the mean returns of these ten contrarian trading rules based on one of the four strategies are less than the mean of the buy-and-hold strategy. In general, Strategy 2 and 4 have higher average daily difference returns than Strategy 1 and 3 which implies that, when a model emits sell signals, the daily difference return will be higher if the trader shorts the market rather than parking the funds in the money market. This, however, does not consider transaction costs of shorting the market. If risk and transaction costs are not considered, then the best strategy would be leverage/short or Strategy 4 and the best contrarian trading rule would be 
the combined contrarian trading rule of EMA20 and EMA50 with extremely high daily difference returns of 0.01160 , or 1.16 percent per day.

Although we have established the predictive power of the contrarian trading rules, this knowledge may not be exploitable without considering transaction costs and risks. One method to determine whether a trader can exploit the predictive power of the contrarian trading rules is to estimate the one-way "break-even" transaction cost (BEC) and risk of various contrarian trading rules for each strategy and compare them with the actual transaction cost and risk of a passive strategy. Do one-way break-even transaction costs eliminate the additional return from contrarian trading rules? Table 5 presents risk and BEC for various contrarian trading rules and for each strategy.

We estimate BEC similar to Bessembinder and Chan (1995) by adding the daily excess returns (beyond buy-and-hold) produced by each strategy over the 1584 days and then divide it by the number of trades (in and out of the market) over the entire period. Since every time a trader shorts the market the number of trades increase by one trade, for Strategies 2 and 4 we divide the sum of daily excess returns by twice the number of trades. The risk of each strategy is estimated by the standard deviation of the daily returns; this risk should be compared to the daily standard deviation of the buy-and-hold or $10.25 \%$ of Table 1.

Table 5: Break-Even Costs and Risk

BEC is the break-even cost, estimated by dividing total daily excess returns into total number of trades over the entire period. Risk is the standard deviation of daily returns.

\begin{tabular}{lcccccccc}
\hline & \multicolumn{2}{c}{ Strategy 1 } & \multicolumn{2}{c}{ Strategy 2 } & \multicolumn{2}{c}{ Strategy 3 } & \multicolumn{2}{c}{ Strategy 4 } \\
\hline Contrarian Rules & BEC \% & Risk \% & BEC \% & Risk \% & BEC \% & Risk \% & BEC \% & Risk \% \\
\hline EMA-20 & 2.45 & 9.81 & 2.29 & 10.23 & 4.65 & 19.62 & 3.39 & 19.82 \\
EMA-50 & 2.81 & 9.92 & 2.58 & 10.23 & 5.27 & 19.85 & 3.81 & 20.00 \\
RSI & 2.53 & 9.87 & 2.35 & 10.23 & 4.77 & 19.74 & 3.47 & 19.92 \\
DMS & 2.73 & 9.81 & 2.53 & 10.23 & 5.14 & 19.61 & 3.74 & 19.82 \\
EMA20 \& DMS & 2.84 & 9.78 & 2.64 & 10.23 & 5.38 & 19.57 & 3.91 & 19.79 \\
EMA20-RSI & 2.63 & 9.81 & 2.45 & 10.23 & 4.99 & 19.61 & 3.64 & 19.82 \\
EMA50 \& DMS & 3.13 & 9.79 & 2.88 & 10.23 & 5.91 & 19.59 & 4.27 & 19.80 \\
EMA50 \& RSI & 2.98 & 9.85 & 2.76 & 10.23 & 5.65 & 19.69 & 4.10 & 19.88 \\
EMA20 \& EMA50 & 3.03 & 9.79 & 2.83 & 10.23 & 5.77 & 19.57 & 4.20 & 19.79 \\
DMS \& RSI & 2.88 & 9.80 & 2.66 & 10.23 & 5.44 & 19.60 & 3.95 & 19.81 \\
\hline
\end{tabular}

The results shown in Table 5 are very strong, and the one-way BECs of all contrarian trading rules for each strategy are very high. The BECs of Strategies 1 and 3 are higher than the BECs of Strategies 2 and 4 implying that it would be better to be in the money market rather than shorting the index when a contrarian rule emits a sell signal. This is because investing in the money market does not incur any transaction costs, whereas shorting the market results in transaction costs that reduce BECs. We, therefore, conclude that Strategies 1 and 3 are superior to Strategies 2 and 4.

As shown in Table 5, when we compare Strategies 1 and 3, the BECs for Strategy 1 is much lower than the BECs for Strategy 3; however the risk of Strategy 3 is almost twice the risk of Strategy 1. The average risk of Strategy 1 and 3 for all 10 contrarian trading rules are $9.82 \%$ and $19.65 \%$, respectively. Results, therefore, indicate that the risk of Strategy 1 on average is a bit lower than the risk of the buy-and-hold strategy, and the risk of Strategy 3 on average is almost twice the risk of the buy-and-hold strategy. These results are very interesting. A trader can choose the risk-return trade off and decide the strategy that would be compatible with his/her risk tolerance. If a trader prefers similar risk as the buy-and-hold strategy, then Strategy 1 should be chosen, assuming this is the best strategy among the four strategies even though a trader with high risk tolerance could possibly choose Strategy 3 (Leverage/Money).

Now let us decide which of the contrarian trading rules are the best for Strategy 1 which has a similar risk as the buy-and-hold strategy. All contrarian trading rules for Strategy 1 have a similar risk of approximately 9.80\%, which is a bit lower than the risk of buy-and-hold (10.24\%). The best trading rules are those rules with highest BECs. For the contrarian trading rules with a single indicator, the best contrarian trading rule is EMA50 with a BEC of $2.81 \%$. The best combined two-indicator contrarian trading rule is EMA50 and DMS with a BEC of 3.13\%. The 
second best one-indicator model is DMS with a BEC of $2.73 \%$, and the second best two-indicator model is EMA20 \& EMA50 with a BEC of 3.03. Domowitz et al. (2001) investigate the transaction costs for 42 countries and their estimate of one-way total transaction costs for average emerging markets and Asian markets are 0.95 and 0.93 percent respectively. The estimated BECs of Strategy 1 for the NSI are much higher than the estimated BECs by Domowitz for emerging and Asian countries, which implies that contrarian technical trading rules could be profitable even after considering transaction costs and risk. An investor can follow Strategy 1, a low risk strategy, and apply the two-indicator contrarian trading rule of EMA50 \& DMS (Best rule) to the NSI to beat the buy-andhold strategy if the investor's one way BEC is less than 3.13\%. An investor can also apply the one-indicator contrarian trading rule EMA50 to beat the buy-and-hold strategy if the investor's one-way break-even cost is less than $2.58 \%$, which is higher than the Domowitz break-even costs. If the investor's risk tolerance is above the risk of the buy-and-hold strategy, the investor can use Strategy 3 and either apply one-indicator model EMA50 or twoindicator model EMA50 and DMS.

\section{CONCLUSION}

This study has applied several well-known and popular technical indicators to the Nairobi Stock Index, and the results of the study support the predictive power of contrarian trading rules. If contrarian trading rules do not have any power to predict index price movements, then the mean buy day returns should not differ appreciably from the mean sell day returns. But, the study concludes that contrarian trading rules do have predictive powers. The second question becomes whether a trader can use this predictive power to beat the profitability of the buy-and-hold strategy considering both transaction costs and risk? The results of this study show that it is possible to design a strategy to beat the buy-and-hold strategy even after considering transaction costs and risk.

\section{AUTHOR INFORMATION}

Massoud Metghalchi, University of Houston-Victoria, School of Business Administration, Department of Finance, 3007 N. Ben Wilson, Victoria, Texas, 77901 USA. E-mail: metghalchim@uhv.edu

John Kagochi, University of Houston-Victoria, School of Business Administration, Department of Economics, 3007 N. Ben Wilson, Victoria, Texas, 77901 USA. E-mail: kagochij@uhv.edu (Corresponding author)

Linda A. Hayes, University of Houston-Victoria, School of Business Administration, Department of Marketing, 3007 N. Ben Wilson, Victoria, Texas, 77901 USA. E-mail: Hayes1@uhv.edu

\section{REFERENCES}

1. Alexander, S. (1964). Price movements in speculative markets: Trends or random walks. Industrial Management Review, 5(2), 25-46.

2. Appel, G. (1974). Publisher of systems and forecast. Signalert Corporation, 150 Great Neck Road, Great Neck, NY 11021.

3. Bessembinder, H., \& Chan, K. (1995). The profitability of technical trading rules in the Asian stock markets. Pacific-Basin Finance Journal, 3, 257-284.

4. Bessembinder, H., \& Chan, K. (1998). Market efficiency and returns to technical analysis. Financial Management, 27(2), 5-17.

5. Brock, W., Lakonishok, J., \& Lebaron, B. (1992). Simple technical trading rules and the stochastic properties of stock returns. Journal of Finance, 47, 1731-64.

6. Chang, Y., Metghalchi, M., \& Chan, C. (2006). Technical trading strategies and cross-national information linkage: The case of Taiwan stock market. Applied Financial Economics, 16, 731-743.

7. Chen, C.W., Huang, C. S. \& Lai, H.W. (2011). Data snooping on technical analysis: Evidence from the Taiwan stock market. Review of Pacific Basin Financial Markets and Policies, 14(2), 195-212.

8. Chong, T., Cheng, S., \& Wong, E. (2010). A comparison of stock market efficiency of the BRIC countries. Technology and Investment, 1, 235-238.

9. Coutts, A., \& Cheung, K. C. (2000). Trading rules and stock returns: Some preliminary short run evidence from the Hang Seng 1985-1997. Applied Financial Economics, 10, 579-686. 
10. Domowitz, I., Glen, J., \& Madhaven, A. (2001). Liquidity, volatility, and equity trading costs across countries and over time. International Finance, 4(2), 221-255.

11. Draper, P., \& Paudyal, K. (1997). Microstructure and seasonality in the UK equity market. Journal of Business Finance and Accounting, 24, 1177-1204.

12. Dunis, C., \& Chen, Y. X. (2005). Alternative relative models for risk management and trading: An application to the EUR/USD and UDS/JPY rates. Derivatives Use, Trading \& Regulations, 11, 126-156.

13. Fama, E. (1965). The behavior of stock market prices. Journal of Business, 38, 34-105.

14. Fama, E. (1970). Efficient capital markets: A review of theory and empirical work. Journal of Finance, 25, 383-417.

15. Fama, E., \& Blume, M. (1966). Filter rules and stock market trading profits. Journal of Business, 39, 226341.

16. Gencay, R. (1998a). Optimization of technical trading strategies and profitability in security markets. Economics Letters, 59(2), 249-254.

17. Gencay, R. (1998b). The predictability of security returns with simple technical trading rules. Journal of Empirical Finance, 5(4), 347-359.

18. Granger, C., \& Morgenstern, O. (1963). Spectral analysis of New York stock market prices. Kyklos, 16, 127.

19. Hsu, P.H., \& Kuan, C. M. (2005). Re-examining the profitability of technical analysis with white's reality check. Journal of Financial Econometrics, 3(4), 606-628.

20. Hudson, R., Dempsey, M., \& Keasey, K. (1996). A note on weak form of efficiency of capital markets: The Application of simple technical trading rules to UK stock prices - 1935 to 1994. Journal of Banking and Finance, 20, 1121-1132.

21. Jensen, M., \& Benington, G. (1970). Random walks and technical theories: Some additional evidence. Journal of Finance, 25, 469-82.

22. Kwon, K., \& Kish, R. (2002). Technical trading strategies and return predictability: NYSE. Applied Financial Economics, 12, 639-53.

23. Lane, G. C. (1985). Lane's Stochastics: The ultimate oscillator. Journal of Technical Analysis, 21, 37-42.

24. Larson, A. (1960). Measurement of random process in futures prices. Food Research Institute, 1, $313-24$.

25. Lesmond, D., Schill, M., \& Zhou, C. (2004). The illusory nature of momentum profits. Journal of Financial Economics, 71, 349-380.

26. Lento, C. (2007). Tests of technical trading rules in the Asian-Pacific equity markets: A bootstrap approach. Academy of Accounting and Financial Studies Journal, 11, 2.

27. Lukac, L. P., Brorsen, B. W., \& Irwin, S. H. (1988). A test of futures market disequilibrium using twelve different technical trading systems. Applied Economics, 20, 623-639.

28. Mandelbrot, B. (1963). The variation of certain speculative prices. Journal of Business, 36, 394-419.

29. Metghalchi, M., \& Chang, Y. (2003). Profitable technical trading rules for the Italian stock market. RivistaInternationale Di Scienze Economiche e Commerciali, L(4), 433-450.

30. Metghalchi, M., Chang, Y., \& Marcucci, Y. (2008). Is the Swedish stock market efficient? Evidence from some simple trading rules. International Review of Financial Analysis, 17(3), 475-490.

31. Metghalchi, M., Chang, Y., \& Marcucci, Y. (2012). Are moving average trading rules profitable? Evidence from the European stock markets. Applied Economics, 12, 1539-1559.

32. Metghalchi, M., \& Garza-Gomez, X. (2011). Trading rules for the Abu Dhabi stock index. Review of Middle East Economics and Finance, 7.

33. Mills, T. C., \& Coutts, J. A. (1995). Calender effects in the London Stock exchange FT-SE indices. European Journal of Finance, 1, 79-93.

34. Nairobi Stock Exchange (NSE). Retrieved June 5, 2013 from http://www.nse.co.ke

35. Osborne, M. (1962). Periodic structure in the Brownian Motion of stock prices. Operations Research, 10, 345-79.

36. Park, C. H., \& Irwin, S. H. (2007). What do we know about the profitability of technical analysis? Journal of Economic Surveys, 21(4), 786-826.

37. Pring, M. J. (1991). Technical analysis: Explained. McGraw-Hill Co.

38. Raj, M., \& Thurston, D. (1996). Effectiveness of simple technical trading rules in the Hong Kong futures markets. Applied Economics Letters, 3, 33-36. 
39. Ratner, M., \& Leal, R. P. C. (1999). Test of technical trading strategies in the emerging equity markets of Latin America and Asia. Journal of Banking and Finance, 23(1), 1887-1905.

40. Ready, M. (2002). Profits from technical trading rules. Financial Management, Autumn, 43-61.

41. Sweeney, R. (1986). Beating the foreign exchange market. Journal of Finance, 41, 163-182.

42. Szakmary, A., Davidson, W. N., \& Schwarz, T. V. (1999). Filter tests in Nasdaq Stocks. The Financial Review, 34, 45-70.

43. Taylor, S. J. (2000). Stock index and price dynamics in the UK and US: new evidence from trading rules and statistical analysis. European Journal of Finance, 6, 39-69.

44. Van Horn, J. C., \& Parker, G. C. (1967). The random walk theory: An empirical test. Financial Analyst Journal, 23, 87-92.

45. Wilder, J. W. (1978). New concepts in technical trading systems. Greensboro, NC: Trend Research.

46. World Bank (2012). World development indicators. Washington, D.C.: The World Bank.

47. Zhou, Y., \& Zhou, G. (2009). Technical analysis: An asset allocation perspective on the use of moving averages. Journal of Financial Economics, 92, 519-544. 


\section{Appendix on Technical Analysis}

The three basic investing methods that most professional investors use are: 1) growth stock approach, 2) value stock approach and 3) technical analysis which is a method of forecasting the future direction of financial asset prices by analyzing statistics generated by market activities, volume, open interest, past prices, and various indicators based on prices and volumes. Advocates of the efficient market hypothesis do not believe in any of the above methods, whereas some professionals such as William O'Neill of Investor Business Daily use a combination of growth and technical approach to investing. Technical analysts do not attempt to measure a security's intrinsic value; instead they look for patterns and indicators on the charts that will determine whether a trader should go long or short or stay neutral for any security. The body of technical indicators is substantial and continues to grow as traders develop new and supposedly better and more complex indicators. This appendix describes the five indicators used in this paper.

Exponential Moving Averages (EMA). One of the most important trend-determining indicators is the moving average (MA) technique. There are three major variations of MA in technical analysis: 1) Simple moving average, 2) Weighted moving average, and 3) Exponential moving average. A simple MA shows the average value of a security's price over a period of time. However, some technicians prefer to give most recent prices more weights than older prices. This can either be done if we use a weighted MA (WMA) or an Exponential MA (EMA). The EMA places a larger weight on information that is more recent. For a more detailed explanation of EMA, see Kirkpatrick II and Dahlquist (2011).

Wilder's Relative Strength Index (RSI). This indicator compares the magnitude of a stock's recent gains to the magnitude of its recent losses. RSI is a ratio of the upward price movement to the total price movement over a given period of days (Wells Wilder suggested 14 days). Given the number of days N, the calculation of RSI is described as follows:

$\mathrm{AU}=$ Average of $\mathrm{N}$ days' up closes

$\mathrm{AD}=$ Average of $\mathrm{N}$ days' down closes

$\mathrm{RSI}=\frac{A U}{A U+A D} \times 100 \quad(\mathrm{RSI}$ is a number between 0 and 100. $)$

In a bull market the RSI is mostly above 50 and in a bear market it is below 50 .

Moving Average Convergence Divergence (MACD). The MACD is a momentum indicator that is calculated by subtracting the value of a 26-period exponential moving average from a 12-period exponential moving average. If MACD is above the zero line, a buy signal is emitted and, when it becomes negative, a sell signal is emitted.

Stochastic. This is another popular indicator. The basic calculation is called the raw stochastic (also known as $\% \mathrm{~K}$ ) that specifies the relative position of the closing price within the range of the previous $\mathrm{N}$ days.

$\% K($ Today $)=100 \times \frac{\text { close }(\text { today })-\text { lowest low of past } N \text { days }}{(\text { high }- \text { low }) \text { range of past } N \text { days }}$

Where $\mathrm{N}$ is the number of days for estimating the indictor. Most people use 14 days for $\mathrm{N}$, but it can be 3, 9, 28, or 33; we use the 14 days in this paper. This $\% \mathrm{~K}$ is the first line (usually bold line). A smoother version of the raw stochastic $(\% \mathrm{~K})$ is known as $\% \mathrm{D}$, which is essentially the moving average 3 of $\% \mathrm{~K}$. We, therefore, have two lines: $\% \mathrm{~K}$ and $\% \mathrm{D}$ lines. A buy signal is emitted, and we will be in the market when $\% \mathrm{~K}$ is above $\% \mathrm{D}$ and $\% \mathrm{D}$ is increasing, otherwise we will be out of the market (sell day). 
Average Directional Movement System. This indicator is based on the comparison of two directional movements (DM), positive DM and negative DM. The standard time period is 14 periods, although other time spans can be used. The estimation is as follows:

Positive directional movement $(\mathrm{PDM})=\mathrm{H}-\mathrm{H}_{\mathrm{P}}$

Negative directional movement $(\mathrm{NDM})=\mathrm{L}_{\mathrm{P}}-\mathrm{L}$

$\mathrm{H}=$ the highest price of the current period

$\mathrm{H}_{\mathrm{P}}=$ the highest price of the previous period

$\mathrm{L}_{\mathrm{P}}=$ the lowest price of the previous period.

$\mathrm{L}=$ the lowest price of the current period.

IF $((\mathrm{PDM}<0$ and $\mathrm{NDM}<0)$ or $(\mathrm{PDM}=\mathrm{NDM})$, then $\mathrm{PDM}=0$ and $\mathrm{NDM}=0)$

$\mathrm{IF}(\mathrm{PDM}>\mathrm{NDM})$, then NDM $=0$

$\mathrm{IF}(\mathrm{NDM}>\mathrm{PDM})$, then $\mathrm{PDM}=0$

We also define True Range as follows:

$\mathrm{TR}=\operatorname{Max}\left(|\mathrm{H}-\mathrm{L}|, \mathrm{H}-\mathrm{C}_{\mathrm{P}}|,| \mathrm{C}_{\mathrm{P}}-\mathrm{L} \mid\right)$

Where $C_{P}$ is the closing price of the previous day. Wilder then uses an exponential smoothing of 1/14 to smooth PDM, NDM and True Range. Wilder defines the Positive directional Index and Negative Directional Index as follows:

$\mathrm{PDI}=\mathrm{SPDM} / \mathrm{STR}=$ Smoothed PDM/Smoothed TR

NDI $=$ SNDM $/$ STR $=$ Smoothed NDM/Smoothed TR

We will be in the market if the value of PDI is greater than the value of NDI (buy day) and will be out of the (sell day) if PDI is less than NDI.

Parabolic Stop And Reversal (PSAR). This is another indicator created by Wilder and, in a bull market, the PSAR is below the price index (Up Trend) and, in a down trend, the indicator is above the price index. When the index is above the PSAR value, we will be in the market (buy day), otherwise we will be out of the market (sell day). PSAR values are calculated as follows:

$\mathrm{SAR}_{\mathrm{t}+1}=\mathrm{SAR}_{\mathrm{t}}+\mathrm{AF}^{*}\left(\mathrm{EP}_{\mathrm{t}}-\mathrm{SAR}_{\mathrm{t}}\right)$

Where $\mathrm{SAR}_{\mathrm{t}}$ is the value of the indicator at time $\mathrm{t}$; $\mathrm{AF}$ is the acceleration factor that increases by 0.02 every time the extreme price is changed and capped at 0.20 as recommended by Wilder. $\mathrm{EP}_{\mathrm{t}}$, or extreme point, is the highest (lowest) price at time $\mathrm{t}$.

In this paper, we use the normal buy and sell signals that were recommended by their creators for the 5 indicators explained above. However, for the contrarian trading rules, we use the opposite of the normal signals in and out of the market. 